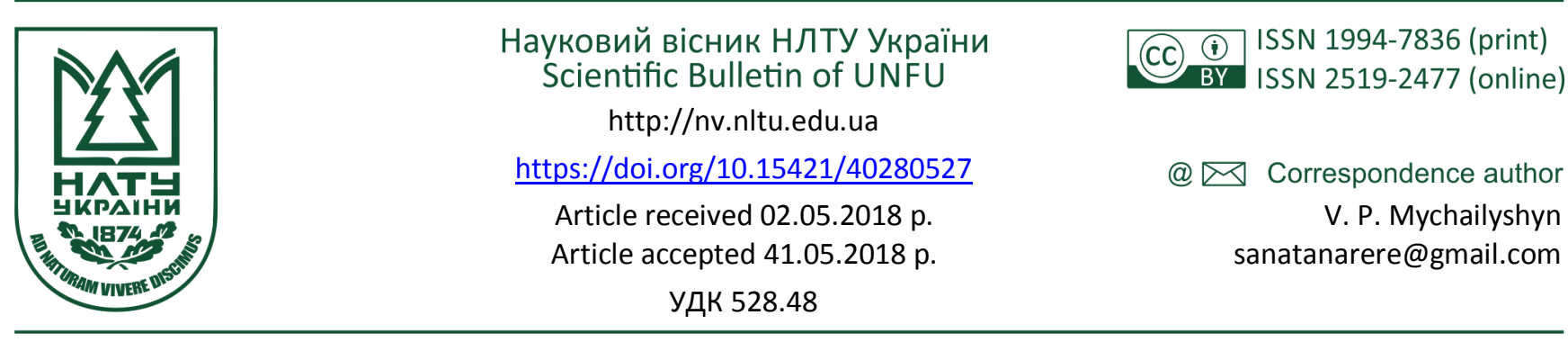

К. О. Бурак, В. П. Михайлишин

Івано-Франківський національний технічний університет нафти і газу, м. Івано-Франківськ, Україна

\title{
СПОСІБ ВИЗНАЧЕННЯ ГЕОМЕТРИЧНИХ ПАРАМЕТРІВ КОЛОВИХ ПІДКРАНОВИХ КОЛІЙ
}

\begin{abstract}
Висвітлено проблеми визначення геометричних параметрів колових підкранових колій. Розглянуто відомі методики контролю геометрії криволінійної підкранової колії. Із появою нових сучасних електронних тахеометрів постало завдання розроблення нового способу вимірювання підкранової колії полярного крана реакторного відділення. Запропоновано нову методику визначення геометричних параметрів колових підкранових колій за допомогою електронного тахеометра, який полягає у визначенні координат точок, замаркованих на колії. На віддалях 20 мм від краю колії з інтервалом у 2,81 м розмічують керном і насвердлюють 48 точок діаметром 3 мм. Виміри виконують 3 трьох станцій, на яких попередньо закріплюють встановлюють три штатива 3 підставками, на яких послідовно встановлюють електронні тахеометри або відбивачі. Вимірювання виконують почергово в секторах $25 \div 7,7 \div 37,12 \div 42,25 \div 42$ і використовують міні-призму. За результатами вимірів аналітично розраховують геометричні параметри колії і дані для оптимального рихтування. Використання способу визначення геометричних параметрів колових підкранових колій згідно з пропонованим винаходом підвищує оперативність проведення виконання геодезичної зйомки, ефективність знаходження геометричних даних та зумовлює зниження витрат часу для одержання результату. За допомогою універсального апроксимуючого алгоритму знайдено радіуси та розраховано дані для рихтування колії колового крана, що допомагає знизити затрати на виконання ремонтних робіт.
\end{abstract}

Ключові слова: реакторне відділення; атомна електростанція; вісь колії; електронний спосіб; віртуальні станції; полярний кран.

Вступ. Колові підкранові колії у РВ АЕС (реакторному відділенні атомних електростанцій) потребують періодичного контролю геометричних параметрів, які доцільно виконувати геодезичними методами. Із практики прикладної геодезії відомо, що контроль геометрії криволінійної підкранової колії $є$ найбільш важко вирішувана задача. Це пояснюють тим, що відсутній алгоритм аналітичного опису фізичних явищ, які можуть бути основою вимірювального процесу криволінійності. Якщо, наприклад, під час визначення параметрів прямолінійності, співвісності, площинності тощо. групуються закономірності прямолінійного поширення світлових променів в оптично прозорому й однорідному середовищі, то природу явищ, які забезпечують формування кривих із відомими або заданими параметрами, ще не розкрито.

Зв'язок роботи з науковими програмами, планами, темами. Всі відомі методики контролю геометрії криволінійної підкранової колії засновані на спеціальних геодезичних побудовах і їх опрацюванню (Burak, 1993; Ruskov, 1994; Buriak \& Buriak, 1995; Pymshyn \& Lytvynova, 1999; Pymshyn \& Lytvynova, 1997). Тобто розпланування досліджуваної підкранової колії на деякі інтервали, закріплення контрольованих точок безпосередньо на ній, виконання вимірювань у системі названих вище точок, опрацювання результатів вимірювань 3 отриманням характеристик кривої і їх достовірності. Також на результати геодезичних вимірів істотний вплив мають коливання повітря, вібрація, перепад температури (Křemen, Koska \& Pospíši, 2017) між рівнем підлоги і рівнем підкранових колій.

Аналіз останніх досліджень та публікацій, що стосуються вирішення цієї проблеми. Відомий спосіб визначення геометричних параметрів колових підкранових колій, який полягає у тому, що позначають вісь колії, як середину рейки, вимірюють віддалі між точками осі колії розташованими рівномірно, визначають за результатами вимірів оптимальний радіус осі колії і відхилення від нього точок осі колії (Burak, 1993).

Але цей спосіб є трудомістким внаслідок застосування 50-метрових рулеток для вимірювання віддалей між точками колії. Він не забезпечує оперативності вимірювань і подальшого контролю рихтування колії. Окрім цього, для проведення вимірів необхідно піднімати або опускати механізми крана.

Також відомий спосіб визначення геометричних параметрів колових підкранових колій РВ АЕС, який полягає в тому, що шукають вісь колії, як середину рейки, за допомогою електронного тахеометра (надалі - ЕT), який встановлюють на крані поблизу проекції "центра ваги колії", вимірюють віддалі до позначених точок і далі, визначивши координати центра, переміщають ЕТ

Інформація про авторів:

Бурак Костянтин Омелянович, д-р техн. наук, професор, завідувач кафедри інженерної геодезії. Email: burak4111945@gmail.com

Михайлишин Володимир Петрович, асистент, кафедра інженерної геодезії. Email: sanatanarere@gmail.com

Цитування за ДСтУ: Бурак К. О., Михайлишин В. П. Спосіб визначення геометричних параметрів колових підкранових колій. Науковий вісник НЛТУ України. 2018, т. 28, № 5. С. 130-134.

Citation APA: Burak, K. O., \& Mychailyshyn, V. P. (2018). The method of determining the geometrical parameters of circular runway. Scientific Bulletin of UNFU, 28(5), 130-134. https://doi.org/10.15421/40280527

130 Науковий вісник НЛтУ України, 2018, т. 28, № 5 Scientific Bulletin of UNFU, 2018, vol. 28, no 5 
до суміщення його осі обертання із знайденою проекцією "центра ваги". Вдруге вимірюють віддалі до точок колії (Patent, 2002).

Варто зазначити, що на колових підкранових коліях PB AЕC України застосувати спосіб недоцільно з огляду на те, що встановити ЕТ поблизу центра ваги фігури на крані дуже важко. Окрім цього, на крані поблизу проекції "центра ваги колії" ні з однієї точки спостереження немає видимості на всі точки колії, тому що заважає його конструкція.

Постановка завдання. Впровадження в геодезичне виробництво електронної техніки дає можливість спростити технологію контролю криволінійних підкранових колій з підвищенням оперативності та об'єктивності контролю. Ця можливість базується на технічних характеристиках сучасних електронних вимірювальних систем. Отож, виникає необхідність створення нового способу визначення геометричних параметрів колових підкранових колій реакторних відділень АС за допомогою ЕТ. Пропонують вимірювати виконувати із площадки, на якій розміщена кругова колія. Правильне розташування ЕТ забезпечить можливість одержання оперативних і об'єктивних даних для оцінки експлуатаційної надійності, що досягається підвищенням точності вимірів (значення радіусів визначення 3 середньоквадратичною похибкою (СКП) $\pm 1,5$ мм).

Виклад основного матеріалу дослідження. Із появою нових сучасних електронних тахеометрів (Karolina, 2010) постало завдання розроблення нового способу вимірювання підкранової колії полярного крана РВ. Його вирішують тим, що вимірювання проводять не оптичними приладами, а ЕТ і не із "центра ваги колії", a iз трьох точок ("віртуальних" станцій), що розміщенні зовні утвореного кола на площадці обслуговування. Місця розташування ЕТ вибирають, щоб під час руху крана штативи були непорушними (Patent, 2015).

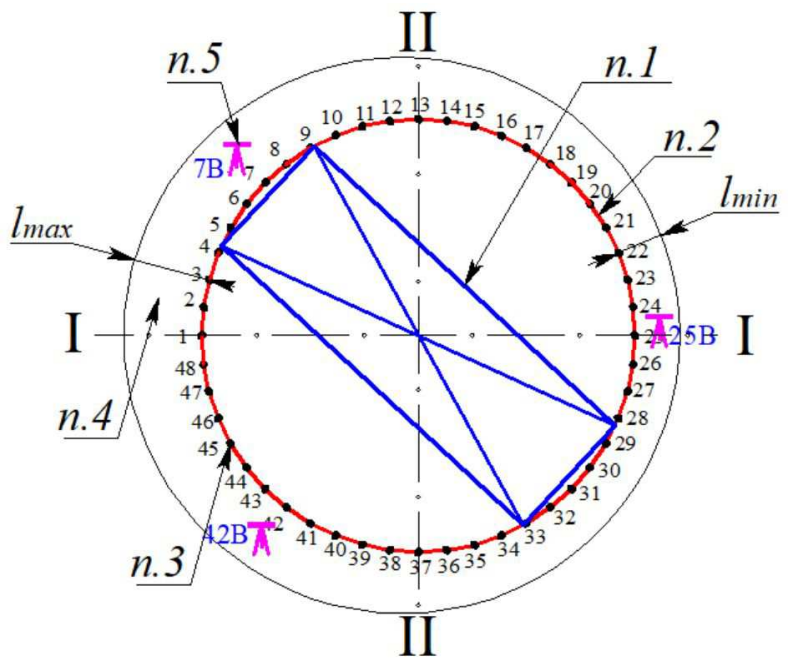

Рис. 1. Нумерація точок на підкрановій колії: п. 1 - мостовий кран кругової дії; п.2 - колова підкранова колія; п.3 - точки на колії; п.4 - площадка обслуговування; п.5 - "віртуальні станції"

Спосіб визначення геометричних параметрів здійснюють так: на віддалях 20 мм від краю колії з інтервалом у 2,81 м розмічують керном і насвердлюють 48 точок діаметром 3 мм (рис. 1). Нумерують точки так, щоб точки 1, 25 приблизно збігалися з напрямком будівельної осі I - I, а точки 37, 13 збігалися 3 напрямком будівельної осі II - II (див. рис. 1). Для кожної точки проводять заміри товщини рейки $-b_{i}$ і віддалі від краю рейки до центра замаркованої точки $-a_{i} 3$ точністю до 0,01 мм. За цими даними підраховують віддалі від центру точки до осі колії

$$
p=0,5 b-a .
$$

Спочатку виставлять мостовий кран кругової дії в початкове положення так, щоб був відкритий сектор точок $7 \div 25$ (див. рис. 1).

На площадці обслуговування - n.4 - встановлюють непорушно на весь час вимірів три штатива 3 тригерами навпроти точок 7, 25 і 42. Штативи потрібно встановлювати так, щоб кран - n. 1 - під час руху за часовою стрілкою не збив їх (для цього їх встановлюють на віддалях $<0,7$ м від захисної оболонки, але так, щоб була можливість зручно взяти відліки). Розміщені тригери - n.5будуть відповідати "віртуальним станціям" 25 В, 7 В і 42 В. Запропоноване розміщення враховує той факт, що підкранову колію змонтовано поза центром відносно ЗОРВ (захисної оболонки реакторного відділення) на 200 мм, тому розміри площадок обслуговування міняються від $l_{\min }=694$ на т. 22 до $l_{\min }=1250$ мм на т. 3.

Визначення геометричних параметрів колових підкранових колій здійснюють за нерухомого крана, який послідовно займає чотири позиції (рис. 2, $a$-2). Під час першого положення крана ET знаходиться на т. 25 В. Послідовно встановлюємо на всіх видимих точках відбивач (див. рис. 2, a) і визначаємо полярним способом координати точок у секторі $25 \div 7$ (варто зазначити, що вимірювання проводимо проти годинникової стрілки, і перша нумерація сектора відповідає розташуванню ET) в умовній системі координат, приймаючи координати станції $X_{T 25 B}=Y_{T 25 B}=0$ дирекційний кут ліній $25 \mathrm{~B}-7 \mathrm{~B}=0^{\circ}$. У пам'яті приладу, окрім умовних координат, записують як значення віддалей, так і дирекційних кутів, за якими в процесі камерального опрацювання результатів вираховують кути з вершиною в т. 25В між послідовними напрямками 7-25B-8, 8-25B-9 тощо. Після виконаних вимірів, ЕТ переміщають на точку 7В. Відбивач послідовно встановлюємо на всіх точках цього ж сектора 7־25 і повторюємо визначення координат полярним способом координат. Варто зазначити, що координати точок, виміряних із станцій $25 \mathrm{~B}$ та 7В, повинні збігаються.

Далі кран повертають за ходом годинникової стріл-

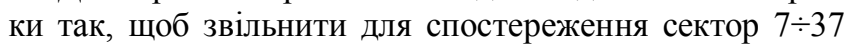
(див. рис. 2, б). ЕТ знаходиться на т. 7В. Аналогічно, як і під час першого положення крана, в умовній системі координат виконують виміри полярним способом координат точок у секторі $7 \div 37$ зі станції 7В. Після чого переставляють ЕТ на станцію 42В.

Далі повертають кран, рухаючись за годинниковою стрілкою, в положення, при якому звільняється сектор $12 \div 42$ (див. рис. 2, в), і зі станції 42В вимірюють координати всіх доступних видимих точок. Після закінчення вимірів ЕТ залишають на станції 42В.

Повертаємо кран за годинниковою стрілкою так, щоб звільнити сектор $42 \div 25$ (див. рис. 2, г) і знаходять координати точок у цьому секторі спочатку із станції 42B, а потім із станції 25B.

Зрівнюємо мережу як лінійно-кутову, приймаючи координати т. 25B і дирекційний кут напрямку т. 25B т. 7В фіксованими значеннями: $X_{T 25 B}=Y_{T 25 B}=0 ; X_{T 7 B}=$ $S_{25 B-7 B} ; Y_{T 7 B}=0$, де $S_{25 B-7 B}-$ середнє значення з 4 виміряних довжин у прямому й оберненому напрямах (розбіжності більше 1 мм не допускають). 

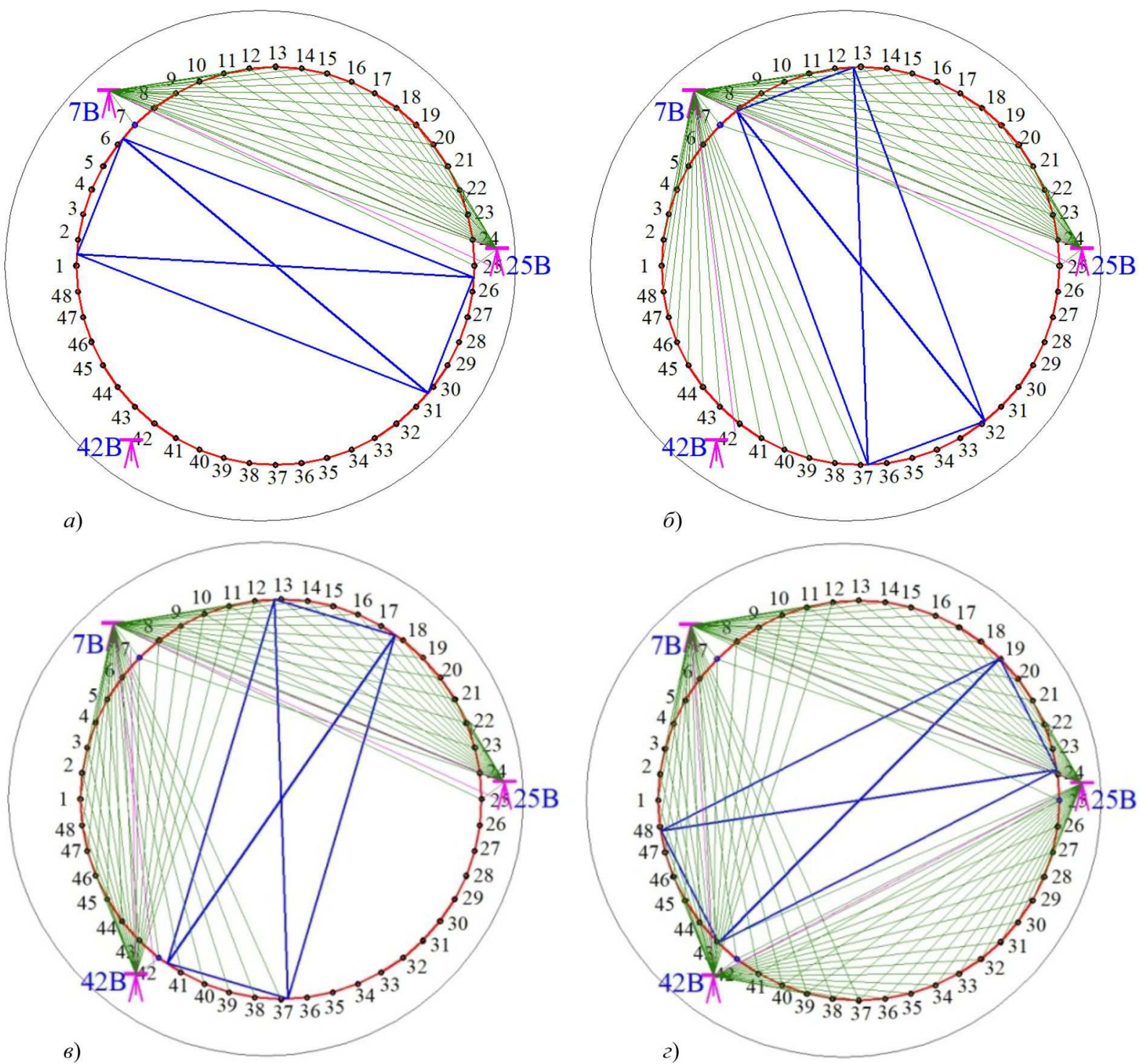

Рис. 2. Розміщення полярного крана для спостереження сектора: $\mathrm{a}-25 \div 7$, б $-7 \div 37$ в $-12 \div 42$, г $-25 \div 42$

Визначають координати точок мережі $1 \div 48$ за всіма виміряними довжинами (окрім 25B-7B) і всіма виміряними кутами між напрямками за різницями відповідних дирекційних кутів. Для цього дані з ЕТ передають через USB порт у пам'ять РC, конвертують у документ формату xls, де i виконують зрівнювання параметричним способом.

За зрівняними координатами точок мережі та з урахуванням (1) знаходять значення радіусів і діаметрів підкранової колії. Для цього використовують універсальний апроксимуючий алгоритм (Burak, 2009) для оцінки геометричних параметрів споруд колової форми, за допомогою якого знаходять положення центру апроксимуючого кола $-x_{0}, y_{0}-$ та його апроксимуючого радіуса $-R$, які дають змогу досягати умови мінімізації середньоквадратичних відхилень, обчислених з урахуванням координат точок колії, радіусів $-R_{i}^{\text {обч }}-\mathrm{i}$ апроксимуючого радіуса $-R$ :

$$
F\left(R, x_{0}, y_{0}\right)=\sum\left[R-R_{i}^{o \sigma u}\right]^{2} \rightarrow \min ,
$$

де:

$$
\begin{gathered}
R_{i}^{\text {обч }}=\sqrt{\left(x_{i}-x_{0}\right)^{2}+\left(y_{i}-y_{0}\right)^{2}}, \\
R=\sum_{i=1}^{N} R_{i}^{\text {обч }} / N,
\end{gathered}
$$

де $N$ - кількість точок із відомими координатами $y_{i}, x_{i}$.

$$
\begin{gathered}
x_{0}=x_{L}-R \cos \alpha_{i} ; y_{0}=y_{\amalg}-R \sin \alpha_{i} ; \\
x_{L}=\sum_{i=1}^{N} / N ; y_{\amalg}=\sum_{i=1}^{N} / N,
\end{gathered}
$$

де $x_{ц}, y_{ц-}$ координати центру тяжіння всієї системи точок

$$
\begin{aligned}
& \cos \alpha_{i}=\sum^{N}{ }_{i=1}\left[\left(x_{i}-x_{0}\right) / R_{i}{ }^{\text {обч }}\right] / N, \\
& \cos \alpha_{i}=\sum^{N}{ }_{i=1}\left[\left(y_{i}-y_{0}\right) / R_{i}{ }^{\text {обч}}\right] / N,
\end{aligned}
$$

які можна розглядати як середнє значення косинуса й синуса кутів, під якими видно точки $x_{i}, y_{i}$ iз центру кола $x_{0}, y_{0}$.

Враховуючи те, що початкові значення $R, x_{0}, y_{0}$ нам відомі 3 високою точністю, то для строгого рішення запропоновано ітераційний метод:

$$
\begin{aligned}
& x_{0}{ }^{(n+1)}=0,5 x_{0}{ }^{(n)}+0,5\left(x_{Ц}-R^{(n)} \cos \alpha_{i}\right) ; \\
& y_{0}{ }^{(n+1)}=0,5 y_{0}{ }^{(n)}+0,5\left(y_{Ц}-R^{(n)} \sin \alpha_{i}\right) ;
\end{aligned}
$$

де $R^{N}=\sqrt{\left(x_{i}-x_{0}\right)^{2}+\left(y_{i}-y_{0}\right)^{2}}-$ наближення до $R$ на $n$ ітерації, а середні косинуси й синуси обчислюють за формулами (5) з урахуванням підстановки замість координат центру кола їх наближення $x_{0}, y_{0}$.

Процес (6) можемо також представити у формі градієнтного методу:

$$
\begin{aligned}
& x_{0}{ }^{(n+1)}=x_{0}{ }^{(n)}+0,5\left(x_{Ц}-x_{0}{ }^{(n)}-R^{(n)} \cos \alpha_{i}\right) ; \\
& y_{0}{ }^{(n+1)}=y_{0}{ }^{(n)}+0,5\left(y_{Ц}-y_{0}{ }^{(n)}-R^{(n)} \sin \alpha_{i}\right) ;
\end{aligned}
$$

звідки видно, що координатна поправка на кожній ітерації дорівнює половині відповідного значення антиградієнта. 
Тому швидкість збіжності процесу (7) залежить від характеру розміщення точок. Якщо точки знаходяться досить близько до деякого кола й рівномірно за кутом, то вибір у якості початкового наближення центра кола, координат центра тяжіння фігури, яку утворюють точки, забезпечує хорошу збіжність.

Після цього розв'язуємо задачу із використанням усіх $N$ точок $y_{i}, x_{i}$. Потім у розв'язок не включається одна точка, у якій одержуємо максимальне відхилення від апроксимуючого кола. I так доти, поки всі точки, що залишились, не будуть знаходитись в допуску.

Знайдені значення дають змогу розв'язати задачу знаходження даних для рихтування, які забезпечують мінімальні затрати на його рихтування.

Висновки. Запропонований спосіб забезпечує визначення геометричних параметрів кругових колій 3 необхідною точністю, підвищує ефективність і оперативність одержаних результатів за рахунок виключення операцій примусового центрування приладу як у точці, що збігається 3 проекцією центра ваги колії, так і на трьох станціях, у яких пропонуємо вести зйомку. Забезпечується можливість систематичних спостережень за замаркованими на колії точками завдяки тому, що їх розміщують не на осі колії, а в місцях, де колія не деформується під дією ходових коліс.

За допомогою універсального апроксимуючого алгоритму знаходимо радіуси та розраховуємо дані для рихтування колії колового крана, що дає змогу знизити затрати на виконання ремонтних робіт.

Використання способу визначення геометричних параметрів колових підкранових колій згідно із запропонованою методикою підвищує оперативність виконання геодезичної зйомки, ефективність знаходження геометричних даних та зумовлює зниження витрат часу для одержання результату.

\section{Перелік використаних джерел}

Burak, K. Е. (1993). O kontrole za sostoianyem podkranovoho puty poliarnoho krana reaktornoho otdelenyia AJES. Heodezyia y kartohrafyia, 5, 20-22. [In Russian].

Burak, K. O. (2009). Suchasni problemy heodezychnoho kontroliu ekspluatatsiinoi nadiinosti na AES ta metody yikh rozviazannia. Doctoral Dissertation for Technical Sciences (05.24.01). Lviv, 410 p. [In Ukrainian].

Buriak, K. E., \& Buriak, U. K. (1995). Kontrol heometrycheskykh razmerov poliarnыkh kranov reaktornыkh otdelenyi AJES. Heodezyia y kartohrafyia, 5, 13. [In Russian].

Karolina, S. (2010). Charakterystyka Porownawcza Tachimetrow Elektronicznych Firm: Leica, Nicon, Sokkia, Topcon, South. Retrieved from: http://docplayer.pl/20142422-Charakterystyka-porownawcza-tachimetrowelektronicznych-firm-107-leica-nicon-sokkiatopcon-south.html.

Patent. (2002). Ukraina UA 50117 A. MKP, G01C 3/30. Sposib vyznachennia heometrychnykh parametriv kolovykh pidkranovykh kolii. O. I. Moroz, K. R. Tretiak, P. H. Cherniaha, P. P. Shpakivskyi, T. H. Shevchenko; zaiavnyk i patentoutrymuvach Natsionalnyi universytet "Lvivska politekhnika". № 50117; zareiestr. v Derzh. reiestri patentiv Ukrainy na vynakhid 15.10.2002. 2 p. [In Ukrainian].

Patent. (2015). Ukraina, UA 109673 S2 MPK, G01C 3/30. Sposib vyznachennia heometrychnykh parametriv kolovykh pidkranovykh kolii. K. O. Burak, V.P. Mykhailyshyn, V. M. Kovtun, M.Ya Hrynishak, O. P. Shpakivskyi; zaiavnyk i patentoutrymuvach IFNTUNH. № 109673; zareiestr. v Derzh. reiestri patentiv Ukrainy na vynakhid 25.09.2015. 8 p. [In Ukrainian].

Pymshyn, Yu. Y., \& Lytvynova, L. F. (1997). Razrabotka sposobov kontrolia radyalnosty obъektov. Heodezyia y fotohrammetriia, 43. [In Russian]

Pymshyn, Yu. Y., \& Lytvynova, L. F. (1999). O kontrole heometryy radyalnoho podkranovoho puty. Prykladnaia heodezyia, 78. [In Russian].

Ruskov, A. M. (1994). Sposob opredelenyia radyusa kruhovoho puty poliarnoho krana reaktornoho otdelenyia AJES. Heodezyia y kartohrafyia, 4, 31. [In Russian].

Křemen, Tomáš, Koska, Bronislav, \& Pospíšil, Jiř́i. (2017). Checking of crane rails by terrestrial laser scanning technology. Retrieved from: http://transportation.mst.edu/media/researchtransportation/documents/762 Myers.pdf.

К. Е. Бурак, В. П. Михайлишин Ивано-Франковский национальный технический университет нефти и газа, г. Ивано-Франковск, Украина

\section{СПОСОБ ОПРЕДЕЛЕНИЯ ГЕОМЕТРИЧЕСКИХ ПАРАМЕТРОВ КРУГОВЫХ ПОДКРАНОВЫХ ПУТЕЙ}

Освещены проблемы определения геометрических параметров круговых подкрановых путей. Рассмотрены известные методики контроля геометрии криволинейного подкранового пути. С появлением новых современных электронных тахеометров встала задача разработки нового способа измерения подкранового пути полярного крана реакторного отделения. Предложена новая методика определения геометрических параметров круговых подкрановых путей с помощью электронного тахеометра, который заключается в определении координат точек, замаркированных на пути. На расстояниях 20 мм от края пути с интервалом в 2,81 м размечают керном и сверлят 48 точек диаметром 3 мм. Измерения выполняют с трех станций, на которых предварительно неподвижно устанавливают три штатива с подставками, на которых последовательно устанавливают электронные тахеометры или отражатели. Измерение выполняют поочередно в секторах $25 \div 7,7 \div 37,12 \div 42$, $25 \div 42$ и используют минипризму. По результатам измерений аналитически рассчитывают геометрические параметры пути и данные для оптимальной рихтовки. Использование метода определения геометрических параметров круговых подкрановых путей согласно предлагаемого изобретения повышает оперативность проведения выполнения геодезической съемки, эффективность нахождения геометрических данных и приводит к снижению затрат времени для получения результата. С помощью универсального аппроксимирующего алгоритма находим радиусы и рассчитываем данные для рихтовки пути кругового крана, что позволяет снизить затраты на проведение ремонтных работ.

Ключевые слова: реакторное отделение; атомная электростанция; ось пути; электронный способ; виртуальные станции; полярный кран.

K. O. Burak, V. P. Mychailyshyn

Ivano-Frankivsk National Technical University of Oil and Gas, Ivano-Frankivsk, Ukraine

\section{THE METHOD OF DETERMINING THE GEOMETRICAL PARAMETERS OF CIRCULAR RUNWAY}

The main methods of controlling the geometry of circular runway of polar crane are reviewed. The existence of radiation in the Atomic Power Station premises offers insights into the process of geodesic works. People can access the reactor building only when the reactor is not working. Therefore the developed methods of geodesic measurements should provide the highest quality and reliability of obtained results, as well as partial or full measurements automation. The results of geodesic measurements are 
influenced by the air vibration, oscillation, and temperature drops between the floor and runway rails levels. Deformations of runway rails may lead to the outage of works. With the advent of new modern electronic tacheometers, the task was to develop a new method for measuring the crane track of the polar crane of the reactor compartment. The new method of defining the geometrical parameters of circular runways by the total station is suggested. The method involves defining the coordinates of points that are marked on the runway. The distances $20 \mathrm{~mm}$ from the runway edge with the $2.81 \mathrm{~m}$ interval are marked by the kern, after which 48 points with $3 \mathrm{~mm}$ diameter are drilled. Measurements are taken from three virtual stations with three fixed mount pillars with triggers, on which the electronic total stations or reflectors are installed. Mount pillars should be installed in such a way to protect them from knock down by the crane. For this purpose, they are installed on the distance of more than $0.7 \mathrm{~mm}$ from the protection sheathe, but close enough to take measurements. The geometrical parameters of the runway are analytically calculated according to the measurements results. By using the universal approximation algorithm for estimating the geometrical parameters of circular form constructions, the values of radius, diameters, and data for optimal alignment are found. Defining the geometrical parameters of circular runways by the recommended method increases the geodetic survey efficiency and decreases the time needed to receive a result. This, in turn, will save the resources and costs of the enterprise (Atomic Power Station).

Keywords: reactor department; nuclear power plant; runway axis; electronic method; virtual stations; polar crane. 